
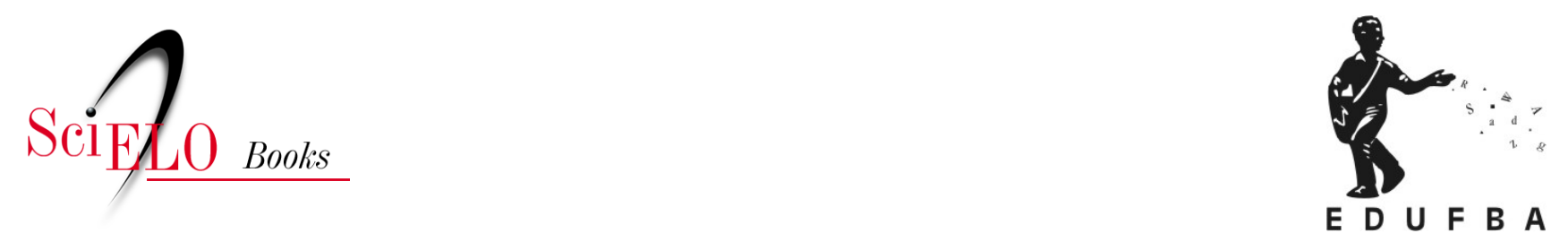

\title{
Parte II - Propostas de ensino \\ Poluição hídrica: uma questão sociocientífica para abordar ética ambiental no ensino fundamental de ciências
}

\author{
Jéssica Santos \\ Dália Melissa Conrado \\ Nei Nunes-Neto
}

SANTOS, J., CONRADO, D.M., and NUNES-NETO, N. Poluição hídrica: uma questão sociocientífica para abordar ética ambiental no ensino fundamental de ciências. In: CONRADO, D.M., and NUNESNETO, N. Questões sociocientíficas: fundamentos, propostas de ensino e perspectivas para ações sociopolíticas [online]. Salvador: EDUFBA, 2018, pp. 191-211. ISBN 978-85-232-2017-4. https://doi.org/10.7476/9788523220174.0009.

All the contents of this work, except where otherwise noted, is licensed under a Creative Commons Attribution 4.0 International license.

Todo o conteúdo deste trabalho, exceto quando houver ressalva, é publicado sob a licença Creative Commons Atribição 4.0. 


\title{
POLUIÇÃO HÍDRICA \\ UMA QUESTÃO SOCIOCIENTÍFICA PARA ABORDAR ÉTICA AMBIENTAL NO ENSINO FUNDAMENTAL DE CIÊNCIAS
}

\author{
Jéssica Santos \\ Dália Melissa Conrado \\ Nei Nunes-Neto
}

\section{Introdução}

A formação de cidadãos críticos e participativos deve ser a principal função da escola. A construção do indivíduo capaz de exercer seus direitos e deveres, de tomar decisões coletivas que permitam maiores justiça social, participação política e sustentabilidade ambiental reflete características da escola, assim como da própria sociedade que a envolve. (BRASIL, 1998; HODSON, 2004; TEIXEIRA, 2003; ZABALA, 1998; ZABALA; ARNAU, 2010) A cidadania não é apenas o exercício de direitos e deveres de um cidadão (como exercer o voto durante as eleições), mas deriva da escolha e da necessidade dos indivíduos para participar de uma organização política e social dinâmica e complexa. Inspirando-nos em convergências de diversos autores - Bencze e Alsop (2009), Conrado e colaboradores (2013), Gorczevski e Martin (2011), Henry Giroux e Susan Giroux (2006), Hodson (2004, 2011) e Santos e Mortimer (2001) -, para nós, a cidadania deve ser compreendida a partir de certas virtudes ou capacidades dos indivíduos para: 
- engajar-se em diálogos críticos com a sociedade e sua história;

- entender criticamente as relações de poder, assim como dos valores e interesses subjacentes aos diferentes grupos sociais;

- reconhecer as complexas inter-relações de forças que se estabelecem nas sociedades; e, por fim,

- participar politicamente das tomadas de decisões de sua sociedade e de ações sociopolíticas diretas e indiretas, visando o bem de indivíduos, sociedades e ambientes, e não apenas seu próprio bem.

A educação sempre está a serviço de um determinado tipo de cidadania. Por exemplo, ela pode atuar para uma formação crítica e reflexiva, fomentando a emancipação popular e as ações efetivas para uma determinada finalidade pactuada e explícita, rumo à maior justiça social e sustentabilidade ambiental; ou, diferentemente, pode ser responsável pela formação de indivíduos acríticos e obedientes, contribuindo para a manutenção de um quadro de imobilismo coletivo diante dos problemas socioambientais. (TEIXEIRA, 2003) Neste âmbito, a escola, como instituição capaz de oferecer contexto para educar e discutir criticamente a respeito dos valores presentes na sociedade, não pode fugir à sua responsabilidade de contribuir na formação de cidadãos críticos. Em particular, em países como o Brasil - que ainda não possui uma democracia madura, tal como as insistentes tentativas, por parte das oligarquias político-econômicas, de desmonte ou fragilização das instituições democráticas, reiteradamente nos lembram -, a discussão de cidadania e educação sobre valores deve estar atrelada às necessidades urgentes de transformação das relações sociais nas dimensões política e econômica, em seus diversos níveis, sempre atentando para a gravidade dos problemas ambientais e sociais, bastante concretos, que nos afligem.

Com o ensino de ciências, não deve ser diferente. Para contribuir com uma formação crítica do cidadão, da nossa perspectiva, pressupõe-se uma abordagem mais ampla e, por isso mesmo, integral do conteúdo nas aulas de ciências, isto é, superando uma abordagem tradicional e tecnicista da educação científica. (ARANHA, 2006; CONRADO; EL-HANI; NUNES-NETO, 2013; FOUREZ, 2008) Em outras palavras, o ensino de ciências deve abordar tanto as dimensões conceitual e procedimental quanto a atitudinal dos conteúdos (COLL et al., 1992; CONRADO; NUNES-NETO, 2015; ZABALA, 1998); o que pode fundamentar-se na perspectiva educacional Ciência, Tecnologia, Sociedade e Ambiente (CTSA).

Nesta linha, cabe notar que há diferentes vertentes na educação CTSA. De acordo com Pedretti e Nazir (2011), estas perspectivas e seus respectivos enfoques são:

- aplicação/design (resolução de problemas da ciência e da tecnologia);

- $\quad$ histórica (compreensão histórica e sociocultural da ciência); 
- raciocínio lógico e argumentativo (compreensão e tomada de decisão sobre Questões Sociocientíficas - QSC);

- raciocínio moral e ético (compreensão e tomada de decisão sobre QSC);

- sociocultural (compreensão da ciência e da tecnologia em um contexto sociocultural amplo);

- justiça social e ambiental (ação sociopolítica para a crítica e a resolução de problemas socioambientais).

Aqui, nos alinharemos mais com aquelas perspectivas que enfatizam a formação do caráter (ZEIDLER et al., 2005) e a educação moral e política como parte de uma educação científica escolar para melhor formação de cidadãos capazes de participação social, de modo responsável e valorizando a coletividade e a justiça socioambiental, o que podemos denominar de ação sociopolítica (HODSON, 2011); em suma, estamos mais alinhados com a quarta e a sexta abordagens, de acordo com a classificação de Pedretti e Nazir (2011). Segundo Hodson (2011), é a capacidade para ação sociopolítica como objetivo do ensino de ciências que levaria a um efetivo letramento científico funcional, também conhecido por letramento científico crítico.

Nesse contexto, enfatizar a dimensão atitudinal dos conteúdos - no âmbito de uma abordagem integral sobre o conteúdo (CONRADO; NUNES-NETO, 2015) - no currículo do ensino de ciências é um modo de preparar cidadãos para ações sociopolíticas (HODSON, 2004), conforme elaboraremos mais adiante. A inclusão de conteúdos atitudinais pode ocorrer na discussão sobre valores morais, interesses político-econômicos e limites da ciência, aproximando esta de uma abordagem humanitária. Assim, a partir de uma reflexão crítica sobre a dimensão moral dos problemas socioambientais, será possível entender que problemas socioambientais não serão resolvidos sem que haja uma necessária mudança de concepção e de hábitos dos próprios agentes sociais, informados e conscientes da responsabilidade de suas ações na sociedade. (HEMPEL, 2014; GRÜN, 2012; JAMIESON, 2010) Diante dos - graves e cada vez menos controlados - problemas socioambientais atuais (BENCZE; CARTER; KRSTOVIC, 2014; BERGANDI, 2013, 2014; WWF, 2014), ressaltamos a necessidade da formação de cidadãos críticos capazes de mobilizar conteúdos científicos no seu cotidiano, a fim de, num primeiro momento, contribuir para compreender criticamente as situações sociais e ambientais complexas que os envolvem; e, num segundo momento, a partir de uma preparação crítica, construir, coletivamente, ações sociopolíticas que contribuam para a solução destes problemas - mais à frente, esta ideia será melhor explicada com base na proposta de currículo em quatro níveis ou estágios de sofisticação, por Hodson (2004).

Neste capítulo, apresentamos uma proposta de ensino baseada em uma questão sociocientífica, como estratégia didática, que contemple conteúdos atitudinais (juntamente com outros conteúdos) para contribuir para um ensino de ciências respalda- 
do pela perspectiva da educação CTSA, visando a melhoria da formação de cidadãos capazes de ação sociopolítica. Nesta linha, discutimos a importância da ética ambiental no ensino de ciências e apresentamos um caso baseado em uma QSC sobre o tema "poluição hídrica", com algumas recomendações para sua aplicação no ensino fundamental de ciências, levando em conta a dimensão ética, proporcionada pela ética ambiental.

\section{Ética ambiental no ensino de ciências}

A ética ambiental nasce, no âmbito da filosofia ambiental, da necessidade de fundamentar filosoficamente o movimento ambientalista, que estava em crescimento acelerado, impulsionado pela crise ambiental, reconhecida na década de 1970. (SILVA, 2009) Além disso, a ética ambiental pode ser vista como uma perspectiva teórica para conceitualizar e sustentar uma política ambiental. (VAZ; DELFINO, 2010) Para isso, a ética ambiental oferece instrumentos e conceitos para reexaminar os conceitos de valor moral frente aos problemas ambientais e se desenvolveu em correntes éticas distintas, baseadas em diferentes noções de valor. Por exemplo, Jax e colaboradores (2013) sugerem uma divisão dos valores que atribuímos à natureza não-humana em: instrumental (que tem utilidade para alguém); eudaimonístico (relacionado ao bem-estar humano); fundamental (relacionado às condições básicas de existência de vida no planeta); e, por fim, inerente (relacionado à própria existência).

Figura 1 - Um mapa dos valores em ética ambiental

\begin{tabular}{|c|l|}
\hline $\begin{array}{l}\text { Valores da natureza } \\
\text { não-humana }\end{array}$ & $\begin{array}{l}\text { Valor inerente } \\
\text { consideração dos seres naturais não-humanos para seu próprio bem e por } \\
\text { sua própria existência }\end{array}$ \\
\hline $\begin{array}{l}\text { Valor fundamental } \\
\text { consideração de condições básicas para existência da vida (humana e } \\
\text { não-humana) na Terra }\end{array}$ \\
$\begin{array}{l}\text { Valor eudaimonístico } \\
\text { consideração de condições básicas para uma boa vida humana }\end{array}$ \\
$\begin{array}{l}\text { Valor instrumental } \\
\text { consideração de algo como meio para alguma outra finalidade (em } \\
\text { princípio, é substituível) }\end{array}$ \\
\hline
\end{tabular}

Fonte: adaptada de Vaz e Delfino (2010) e Jax e colaboradores (2013). ${ }^{1}$

1 O que Jax e colaboradores (2013) consideram valor inerente, Vaz e Delfino (2010) consideram valor intrínseco. O valor intrínseco é entendido como o valor que uma determinada coisa tem devido à sua própria natureza: "As coisas são intrinsecamente valiosas, mesmo na ausência de outros mo- 
A fim de esboçar uma primeira distinção, podemos dividi-la em ética antropocêntrica e ética não-antropocêntrica. (VAZ; DELFINO, 2010) Numa visão antropocêntrica, somente os seres humanos são considerados moralmente; deste modo, os seres vivos não-humanos, assim como o ambiente abiótico, são considerados apenas como instrumento para a obtenção de conforto e qualidade de vida humana e o exame moral recai somente sobre ações que afetam os seres humanos. (VAZ; DELFINO, 2010; NORTON, 2003) Em outras palavras, numa visão antropocêntrica em ética ambiental, os seres humanos são o centro da consideração moral e qualquer outro ser só é considerado moralmente de forma indireta, pelo benefício que gera para os humanos. Uma visão antropocêntrica mais fraca é a apresentada por Bryan Norton (1984). Ele considera que a ética não precisa recorrer ao valor intrínseco da natureza, mas a uma preocupação com a proteção da base dos recursos ao longo do tempo. (LIGHT; ROLSTON Ill, 2003; NORTON, 2013) O antropocentrismo é a principal tradição moral do Ocidente, tendo sido, sobretudo, fortalecido pelos pensamentos de Descartes e Bacon, entre outros, em meio ao projeto de articulação da ciência moderna, no século XVII.

As perspectivas éticas não-antropocêntricas consideram que a proteção da natureza deve acontecer em função dela mesma e não somente em razão dos seres humanos. (VAZ; DELFINO, 2010) Para fins didáticos, podemos dividir as correntes não-antropocêntricas em dois grandes grupos: biocentrismo e ecocentrismo.

O biocentrismo tem como centro da consideração moral a vida e surge como uma corrente divergente ao antropocentrismo (TELES, 2007), no sentido de, simplesmente, alterar a consideração moral, para ampliá-la na medida em que todos os seres vivos são considerados moralmente. Consideraremos três perspectivas biocêntricas. ${ }^{2}$ A primeira é aquela proposta por Paul Taylor (1981), em que o autor considera que o dever humano de preservar as espécies e de evitar a poluição e o desequilíbrio da natureza é a forma de manter a vida saudável de outras espécies, além da nossa. (BECKERT, 2004; VAZ; DELFINO, 2010) Seus princípios fundamentais são:

- Igualdade entre todos os membros da comunidade biótica, incluindo o homem;

- Interconexão entre todos os ecossistemas;

- Consideração de cada ser vivo como centro teleológico que tem um bem próprio a ser realizado;

tivos, quando há razões para promover, apreciar ou proteger por causa da sua própria natureza". (VAZ; DELFINO, 2010, p. 36)

2 Nossa caracterização das três abordagens como biocêntricas não é exata, mas apenas aproximada, pois, como veremos as perspectivas de Peter Singer e Tom Regan, cada uma, a seu modo, restringe a consideração moral a um conjunto menor do que aquele dos seres vivos como um todo. Contudo, apesar desta ligeira imprecisão, todas as três perspectivas coincidem em dois pontos: primeiro, obviamente, ampliam o escopo da consideração moral para além do antropocentrismo; e, segundo, tratam indivíduos - e não totalidades ecológicas - como os objetos de consideração moral. 
- Rejeição de todas as visões antropocêntricas. (BECKERT, 2004; TAYLOR, 1981)

Isto implica que não devemos julgar a natureza através dos padrões humanos, valorizando nela aquilo que está mais próximo de nós ou de nossas necessidades, mas através dos seus próprios padrões, daquilo que constitui o bem para cada ser vivo. (BECKERT, 2004)

A segunda perspectiva biocêntrica que consideramos aqui é aquela proposta por Peter Singer (2010), bem conhecida no campo da ética animal. Ela é baseada no utilitarismo (uma teoria ética consequencialista), e segundo ela, as ações humanas relacionadas aos animais não-humanos devem levar em conta os interesses destes, como parte dos interesses dos envolvidos com tais ações (ou seja, os interesses humanos não são os únicos relevantes). Isto leva Singer (2002) a defender o princípio segundo o qual os interesses de animais humanos e não-humanos devem ser igualmente considerados. Neste sentido, na perspectiva utilitarista de Singer, os interesses estão relacionados ao conceito de senciência, isto é, a capacidade de sentir prazer ou dor, que caracteriza o grupo com estatuto moral, ou seja, que deve ser considerado moralmente. Não sentir dor é um interesse dos animais, humanos ou não-humanos, assim como também continuar vivendo. Obviamente, o respeito a estes interesses por parte dos seres humanos - e assim, o princípio da igualdade de consideração de interesses - não se manifesta quando, a fim de satisfazer seus próprios interesses secundários (como se verifica, cotidianamente, no ato humano de comer outros animais), seres humanos privam os animais não-humanos de seus interesses primários (por exemplo, continuar vivendo, ao invés de ser morto para ser utilizado como alimento).

Por fim, como terceira perspectiva biocêntrica, consideramos a teoria de Tom Regan (2003, 2013). O autor assume, diferentemente de Singer, uma postura filosófica baseada na ideia de direitos. Para Regan (2013, p. 119), a ideia de direitos deve ser estendida a um grupo de animais que inclui os humanos. Assim, para a pergunta: "quem possui direitos morais?", Regan responde: os "sujeitos-de-uma-vida". O conceito de "sujeitos-de-uma-vida” ilumina, de acordo com Regan, a nossa igualdade moral, uma vez que ele aponta para as características que nós humanos temos em comum com outros animais (de modo similiar ao que ocorre com o conceito de senciência). Os "sujeitos-de-uma-vida" são animais que, entre outras características, experienciam o mundo, são capazes de sentir e possuem sua própria história, ao longo da vida. Como Regan (2013, p. 120) afirma: "do ponto de vista moral, cada um de nós é igual, porque cada um de nós é igualmente um alguém, não algo, o sujeito-de-uma-vida, não uma vida sem um sujeito”. O grupo de "sujeitos-de-uma-vida" inclui, segundo Regan (2013), todos os mamíferos, aves e, certamente, todos os peixes, muito provavelmente. ${ }^{3}$

3 Para mais explicações, ver Nunes-Neto (2015). 
Por sua vez, o ecocentrismo tem como principal objeto de consideração moral a coletividade natural, ou seja, todo o conjunto de relações entre os organismos e seu ambiente físico-químico. (BECKERT, 2004; VAZ; DELFINO, 2010) O ecocentrismo tem como respaldo científico a ecologia e um novo modo de enxergar a moralidade que reconhece a primazia moral dos totais ecológicos. (BLANDIN, 2013; JAMIESON, 2010; LARRERE, 2013) Neste sentido, ele é uma ética holista, diferentemente das éticas biocêntricas, que, por estarem focadas em indivíduos portadores de certas capacidades ou disposições, são conhecidas como individualistas. (NUNES-NETO, 2015)

Uma vez que a QSC que nos ocupa neste capítulo é a poluição hídrica, nossa preocupação deve estar focalizada sobre os corpos d'água, ao invés de estar focalizada sobre os indivíduos biológicos de forma direta; em consequência, nos parece mais apropriada a adoção de uma perspectiva ecocêntrica. Por sua vez, a ética ecocêntrica encontra respaldo científico na ciência da ecologia e, mais precisamente, em um conceito epistemologicamente central para a ecologia, o conceito de função. (CAPONI, 2010; NUNES-NETO, 2013; NUNES-NETO; CARMO; EL-HANI, 2013, 2016; NUNES-NETO; MORENO; EL-HANI, 2014) Por isso, é importante abordar o conceito de função aplicado aos sistemas ecológicos e, daí, derivar uma reflexão sobre o valor da água, como um componente relevante dos sistemas ecológicos.

Para De Groot, Wilson e Boumans (2002), as funções dos ecossistemas podem ser classificadas em:

- Funções de regulação - relacionadas à manutenção de todos os ciclos biogeoquímicos pelos organismos vivos e não vivos através de suas interações e processos;

- Funções de habitat - relacionadas ao provimento de abrigo de animais e plantas selvagens, por exemplo;

- Funções de produção - relacionadas à conversão de micronutrientes em macronutrientes através de processos biológicos como a fotossíntese; e

- Funções de informação - relacionadas às fontes de informação humana para aquisição de conhecimentos para a saúde humana, reflexão, desenvolvimento cognitivo, recreação, a partir da interação com os sistemas ecológicos. ${ }^{4}$

Quanto aos tipos de valor associados aos sistemas ecológicos, De Groot, Wilson e Boumans (2002) consideram três categorias:

4 Para mais detalhes sobre o conceito de função em ecologia, assim como suas extensões sociais, éticas e econômicas, recomendamos a consulta dos seguintes trabalhos: Millennium Ecosystem Assessment (2005); Jax (2005, 2010); Nunes-Neto (2013); Nunes-Neto e colaboradores, (2013, 2014); e Cooper; El-Hani e Nunes-Neto (2016). 
- Valor ecológico - determinado pela integridade da função de regulação e função de habitat dos ecossistemas e definidos por parâmetros ambientais, tais como a complexidade do ecossistema, diversidade e raridade;

- Valor econômico - é atribuído aos serviços de mercado que as funções ecossistêmicas fornecem à humanidade, principalmente as funções de produção, que servem de troca monetária no mercado;

- Valor sociocultural - determinado pela medida em que os ecossistemas naturais e suas funções podem contribuir para benefícios sociais, tais como saúde física e mental, educação, diversidade cultural, identidade e liberdade.

Nessa perspectiva, a ideia de que a natureza tem a função de ser fonte de bens e recursos ambientais para humanidade e que, portanto, deve ser dominada para usufruto humano tem nos colocado como principais protagonistas da crise ambiental atual. (SINGER, 2002) Em particular, o predomínio da noção de valor instrumental da natureza, em relação à noção de valor intrínseco da natureza, é uma das chaves para entender a - cada vez mais intermediada por atribuições de valor econômico - consideração moral da natureza pela humanidade. (GÓMEZ-BAGGHETUN et al., 2010; MCCAULEY, 2006)

Inúmeras são as tentativas humanas nos debates sobre mudanças ambientais de negar a sua contribuição para a atual crise ambiental. Isto indica que, enquanto a humanidade não entender que a principal fonte dos problemas ambientais é de natureza ética, acreditaremos no erro de que a ciência e a tecnologia poderão dar conta de solucionar todos os problemas ambientais, sem que sejam necessárias mudanças profundas de concepção, valores, normas e de hábitos (GRÜN, 2012), além de mudanças estruturais nas bases econômicas e de organização política de nossas sociedades. (BERGANDI, 2013, 2014)

Nos debates de ética ambiental, no entanto, não existe uma concordância óbvia na escolha ou na aprovação de uma teoria, devido ao grande número de valores ou perspectivas que se opõem entre si; como fica claro, por exemplo, nos dilemas entre uma teoria individualista e uma teoria holista: a consideração moral de totalidades ecológicas, por vezes, implica a negligência ou desconsideração de indivíduos (como em práticas de manejo baseadas em caça); porém, por outro lado, a consideração moral de indivíduos, se por um lado positiva, pode não implicar por si só a proteção das totalidades ecológicas. (NUNES-NETO, 2015) Ou ainda, outro exemplo, como na oposição entre valor intrínseco e valor instrumental da natureza, tal como eloquentemente expõe Patrick Blandin (2013, p. 93): "nós desejamos preservar a biosfera porque nós valorizamos a vida por si mesma ou por que a continuação dos processos ecológicos na Terra é necessária para a continuação da existência da nossa própria espécie?".

Como agentes morais, somos capazes de distinguir, sobretudo em casos mais simples, de uma forma ou de outra, as condutas eticamente recomendáveis das eticamente 
reprováveis. (SILVA, 2009) Contudo, perante casos complexos, surgem amplas divergências sobre qual conduta é a mais correta ou recomendável moralmente. Tais posicionamentos morais variam, desde uma postura mais consequencialista, a uma mais orientada por virtudes, ou ainda a uma postura mais deontológica (Kantiana), tal como expôs Jamieson (2010, p. 126):

Imaginemos um caso típico que poderia provocar reflexão moral. Suponhamos que John está trocando o óleo de seu carro e joga o óleo do motor usado no bueiro da rua. Um consequencialista irá focar na consequência do ato de John, a respeito do dano que essa ação irá causar ao meio ambiente. Um eticista da virtude irá pensar que tipo de caráter tem John para cometer tal ato. Um kantiano tentará entender o ato de John, o que achou que estava fazendo, quais eram seus motivos.

O posicionamento ético de uma pessoa está intimamente relacionado à sua formação pessoal, a qual será sempre influenciada por diferentes correntes éticas, mesmo que inconscientemente. Por isso, uma formação explícita em ética ambiental e valores é relevante para que os cidadãos tenham maior repertório de ideias e argumentos para compreender e lidar, nos contextos sociais e políticos em que vivem, com os problemas socioambientais. Além disso, uma formação que contextualize ideias abstratas - como as presentes nas teorias morais - em casos socioambientais concretos também será necessária.

Neste sentido, o ensino de ciências tem - na sua conexão ou nas suas intersecções com o ensino de filosofia ou com a própria filosofia moral - uma ótima oportunidade para abordar questões morais e assim ser mais capaz de conduzir a um processo de letramento científico crítico (HODSON, 2004), pois terá de incorporar explicitamente, nos conteúdos curriculares, os conteúdos (ou dimensões) atitudinais (ZABALA, 1998): os valores, atitudes e normas. Reconhecer conteúdos (ou dimensões) atitudinais significa reconduzir o ensino de ciências aos objetivos gerais que se propõe, efetivamente, nos documentos curriculares nacionais brasileiros - Parâmetros Curriculares Nacionais (PCN); Parâmetros Curriculares Nacionais para o Ensino Médio (PCNEM) - : ensinar para uma cidadania responsável, participativa e crítica sobre os problemas socioambientais atuais, de modo a transformar a sociedade, fundamentada em valores de justiça socioambiental. (HODSON, 2011)

Apesar de debruçar-se, como qualquer filosofia, sobre questões abstratas - como o significado de valor intrínseco ou a definição teórica de "sujeitos-de-uma-vida" -, não podemos esquecer que a ética ambiental é também uma ética aplicada. Assim, ela ocupa-se de questões concretas. Uma destas questões diz respeito à água, mais especificamente à poluição hídrica, a QSC abordada neste capítulo, que consideraremos na próxima seção. 


\section{Problemas socioambientais envolvendo a água e a poluição hídrica}

Cerca de $70 \%$ da cobertura do planeta é de água. De toda água existente no planeta, $97,5 \%$ é formado por água salgada. Por sua vez, a disponibilidade de água doce é irregular no planeta, pois $68,9 \%$ estão indisponíveis nas geleiras, calotas polares ou em regiões montanhosas, 29,9\% em águas subterrâneas, 0,9\% compõe a umidade do solo e dos pântanos e apenas $0,3 \%$ constitui a porção superficial de água doce presente em rios e lagos mais acessível ao consumo humano. (VICTORINO, 2007) Segundo o Programa Hidrológico Internacional da Organização das Nações Unidas para a Educação, a Ciência e a Cultura (Unesco), na América do Sul encontram-se 26\% do total de água disponível no planeta, ao passo que, nesta região, encontram-se apenas $6 \%$ da população mundial. (BRASIL, 2005)

Por sua vez, o Brasil abriga 13,7\% da água doce do planeta, que está distribuída no território de modo não uniforme. Cerca de 70\% do percentual de água doce do Brasil se encontra na bacia Amazônica, onde vive apenas $5 \%$ da população humana brasileira, enquanto que a região com maior população, o Sudeste, com $42,65 \%$ da população, detem $6 \%$ da água doce. Cabe notar que, no Brasil, o grande desafio do abastecimento das grandes metrópoles ou aglomerados urbanos está relacionado à frequente utilização de fontes hídricas comuns, o que resulta em conflitos pelo uso da água, de ordem quantitativa e qualitativa. Por exemplo, $61 \%$ do total de municípios brasileiros são abastecidos por mananciais superficiais; nos grandes centros urbanos, como São Paulo, Curitiba, Goiânia, Distrito Federal e Fortaleza, existe a necessidade de buscar mananciais cada vez mais distantes e de investimentos em obras de regularização, o que evidencia a forte pressão sobre a água no Brasil. (AGÊNCIA NACIONAL DE ÁGUAS, 2010)

Entre os principais problemas relacionados ao consumo da água, estão a poluição hídrica, os desperdícios, o consumo irresponsável e as elevadas demandas de água por certas atividades industriais e agrícolas. (BRASIL, 2005)

Consideremos, por ora, a poluição hídrica. A poluição hídrica é comumente consequência das atividades humanas desenvolvidas nas bacias hidrográficas, nos oceanos e mares ou no seu entorno. Entre as principais fontes poluidoras, estão o lançamento de esgotos domésticos, a recepção de água da chuva, que escoa das áreas agrícolas e do efeito de erosão do solo, recepção da água da chuva proveniente de regiões com poluição atmosférica, a exemplo da chuva ácida, percolação do chorume de lixões, compostos tóxicos oriundos de pesticidas utilizados na agricultura e no reflorestamento e águas contaminadas por xenobióticos, compostos orgânicos resistentes e traços de produtos farmacêuticos. (GALLI; ABE, 2010)

Por sua vez, quanto às altas demandas de água, é relevante examinar as contribuições da agricultura e da pecuária. (HOEKSTRA; MEKONNEN, 2012) A agricultura e a pecuária consomem cerca de dois terços da água doce do planeta, através da água da chuva, da água retida no solo e do uso indiscriminado da irrigação. No Brasil, a agricultura é a principal atividade humana responsável por consumir mais água, e somado 
com a pecuária e a siderúrgica é considerado o maior exportador de água. (DETONI; DONDONI; PADILHA, 2007)

Neste contexto, ao avaliar o consumo de água doce com base em seus usos diretos e indiretos, cabe fazer referência a uma ferramenta de gerenciamento de recursos hídricos denominada pegada hídrica (do inglês, water footprint). Tal ferramenta permite que empresas públicas e privadas, e também a população, em geral, entendam a quantidade de água necessária para a fabricação de produtos desde a sua produção até o consumidor final. Em dados publicados por Mekonnen e Hoekstra (2011) tendo como base o período de 1996 a 2005, a pegada hídrica da humanidade demonstra que o consumo de água está fortemente relacionado ao nível de desenvolvimento do país e com o nível de renda das pessoas. O consumidor médio nos Estados Unidos tem uma pegada hídrica de $2842 \mathrm{~m}^{3}$ /ano per capita, enquanto que um cidadão comum na China e na Índia tem pegadas hídricas de 1071 e $1089 \mathrm{~m}^{3}$ /ano per capita, respectivamente. O Brasil possui uma pegada hídrica de $2027 \mathrm{~m}^{3}$ /ano per capita, sendo que cerca de $9 \%$ da sua pegada hídrica total é água virtual, ou seja, está fora das fronteiras do país (ver Figura 2).

O estudo de Mekonnen e Hoekstra (2011) ilustra também a dimensão global do consumo e da poluição, mostrando que vários países dependem fortemente de recursos hídricos estrangeiros devido ao alto consumo de água virtual importada de cereais e carne; ${ }^{5}$ e que muitos países têm impactos significativos sobre o consumo de água e da poluição em outro lugar. (HOEKSTRA; MEKONNEN, 2012)

Figura 2 - Pegada hídrica do consumo nacional (em metros cúbicos por ano per capita, para o período 1996-2005) para alguns países com uma população maior do que 5 milhões

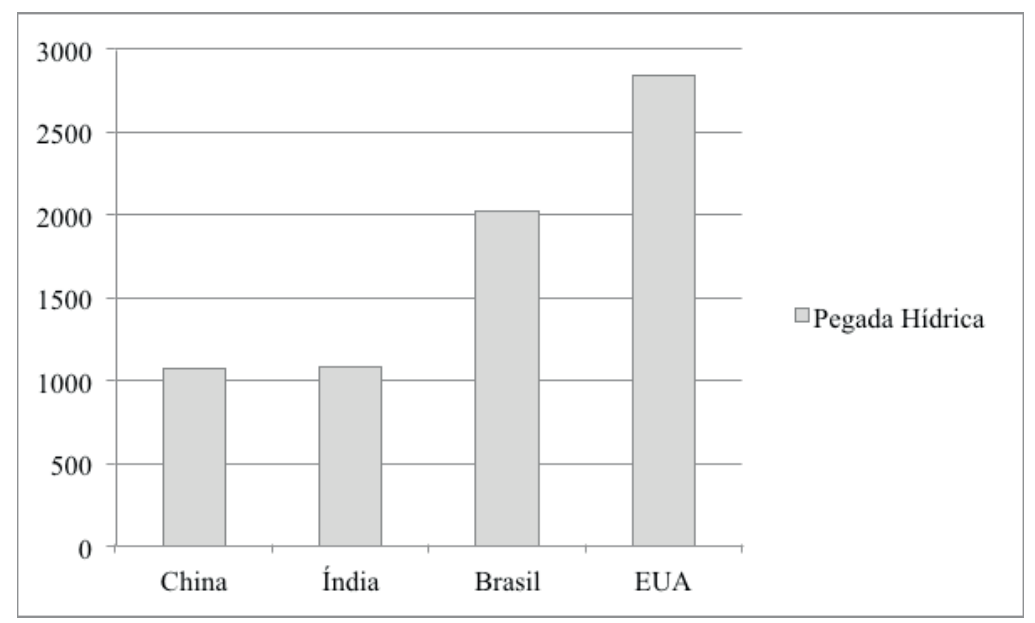

Fonte: adaptada de Hoekstra e Mekonnen (2011).

5 "Água virtual" é uma expressão utilizada para se referir à água presente na produção de alimentos e produtos industrializados. Assim, a exportação de certos bens da agropecuária consiste também numa exportação indireta de água. 
Os problemas descritos acima nos permitem perceber a gravidade da situação em que nos encontramos, com relação à água. Assim, não é surpreendente que, diante do quadro alarmante, tenha ocorrido uma preocupação geral com a água. A declaração ministerial em Haia, do mês de março de 2000, na Holanda, sobre a segurança da água no século XXI é o último marco dessa discussão que se inicia em Mar Del Plata, em 1977, continua em Dublin e foi consolidada no Capítulo 18 da Agenda 21, no Rio de Janeiro em 1992, reafirmada em Paris, em 1998, e no Segundo Fórum Mundial da Água, em Haia. Tais encontros internacionais contribuíram para que cada país elaborasse um plano e medidas em busca da preservação da água e do meio ambiente. No Brasil, desde 1930, existe o Código das Águas; tal código permitia ao poder público controlar e incentivar o aproveitamento industrial das águas. Em concordância com a Conferência das Nações Unidas sobre o Meio Ambiente e Desenvolvimento, também conhecida como ECO92 (a cúpula da Terra, realizada no Rio de Janeiro, em 1992), em 1997, é criada a Lei das Águas, que estabelece o Plano Nacional dos Recursos Hídricos, que tem como um de seus pilares o intenso envolvimento de entidades da sociedade civil na gestão das águas, na criação de comitês e conselhos.

As próprias características da água e do seu ciclo exigem que as problemáticas do seu uso aqui abordadas sejam analisadas e discutidas de forma integrada. Isso significa que questões políticas, econômicas, sociais, ambientais e éticas associadas à água devem ser discutidas de forma articulada nas diferentes escalas: regional, nacional e internacional.

Tendo em vista a relevância ética dos problemas socioambientais associados à água, como, por exemplo, a poluição hídrica, pensamos que esta é uma temática adequada para o ensino de ciências e pode, assim, ser caracterizada como uma QSC.

\section{Um caso a respeito da poluição hídrica}

A proposta de ensino baseada em QSC foi elaborada para o ensino fundamental, no formato de um caso. ${ }^{6}$ Entretanto, ela pode ser utilizada em outros níveis de ensino, como o ensino médio ou, ainda, no ensino superior, desde que devidamente adaptada para o contexto e os objetivos de aprendizagem específicos. Este caso busca mobilizar conteúdos da área da ecologia e da ética ambiental e poderá ser aplicado como parte de uma sequência didática ou, ainda, no ensino não-formal, como parte de um curso de extensão sobre o tema, por exemplo. Ainda, cabe notar que o professor interessado poderá desenvolver um caso, nos moldes do caso apresentado neste capítulo, para abordar a situação de um rio, uma lagoa ou parte da costa litorânea de seu próprio munícipio. Isso permite uma contextualização mais próxima à realidade sociocultural da comunidade escolar.

6 Ressaltamos que a proposta de ensino apresentada compôs parte de uma sequência didática sobre poluição hídrica, aplicada em sala de aula como parte da dissertação de mestrado da primeira autora deste capítulo. Resultados parciais podem ser consultados em trabalhos anteriores: Santos, Conrado e Nunes-Neto $(2015,2016)$. 
Quadro 1 - Caso baseado na QSC sobre poluição hídrica

\section{As águas do Parque São Bartolomeu}

Joana, de 8 anos, saiu acompanhada de sua mãe e outras coleguinhas em visita ao Parque São Bartolomeu. Sua mãe foi ao Parque porque precisava recolher algumas folhas para fazer um remédio com uma planta medicinal e sabia que no Parque poderia encontrar. No caminho, a mãe de Joana contou às meninas que costumava, quando criança, correr pelo parque, subir em árvores, enquanto sua mãe apanhava frutas e folhas.

- Hoje, é preciso muito cuidado, meninas, para andar aqui!

Quando chegou em casa, Joana correu para o colo de sua avó Teresa e the contou o passeio que fez no Parque São Bartolomeu. A menina disse que, apesar do verde, do barulho das águas e dos pássaros, tinha muita sujeira espalhada por todo canto, nas cachoeiras, na mata, que na cachoeira tinha até espuma. A menina ficou bastante assustada e perguntou:

- Vovó, no seu tempo era assim?

Dona Teresa contou à neta:

- No meu tempo, havia mais respeito com as áreas verdes, eram consideradas lugares santos. Nós cuidávamos desses lugares, não jogávamos lixo e esgoto. Não se podia fazer nenhum tipo de violência ali, nem contra os bichos, nem contra as pessoas; senão podíamos ser castigados. Hoje, as pessoas não têm mais respeito por nada, é uma tristeza só. Que pena que o parque não esteja mais bonito para você, minha netinha!

Joana perguntou para sua avó:

- O que podemos fazer para melhorar as condições do parque, vovó?

Fonte: elaborado pelos autores com base em Santos, Conrado e Nunes-Neto (2015, 2016).

Questões relacionadas ao caso sobre a QSC

Q1. Analisando a história vivenciada por Joana e o questionamento dela para com sua avó, quais reflexões podemos fazer?

Q2. Quais problemas estão presentes no Parque São Bartolomeu e de que forma podemos identificá-los?

Q3. Quais problemas presentes no Parque São Bartolomeu interferem em nossas vidas?

Q4. Qual a importância de reservas como a do parque São Bartolomeu para o meio ambiente?

Q5. Que atitudes devemos ter para evitar a poluição hídrica?

Q6. Sobre os problemas sinalizados por Joana, você considera que eles têm relação com a forma pela qual as pessoas se relacionam com o meio ambiente? Por quê?

Q7. Quais as semelhanças e diferenças entre bichos e pessoas, mencionados por Dona Teresa?

Q8. Você acha que a mãe de Joana deveria ir comprar um remédio pronto na farmácia, ao invés de ir coletar folhas e prepará-lo? Por quê? 
Q9. O que podemos fazer para respeitar o parque? O que se pode fazer para reverter a atual situação do Parque São Bartolomeu? Ajude Joana, propondo medidas que solucionariam tais problemas.

\section{Objetivos de aprendizagem}

Nesta seção, apresentamos os conteúdos de aprendizagem, divididos esquematicamente em três dimensões: conceituais, procedimentais e atitudinais. Os conteúdos relacionam-se aos temas de poluição hídrica, desde uma perspectiva da educação CTSA, e assim, constituem, de uma só vez, uma proposta de conteúdos a serem abordados nas áreas de ecologia e ética ambiental.

\section{Conceituais}

- Discutir e compreender: fatos históricos sobre o Parque São Bartolomeu, a partir de dados empíricos sobre ele; fatos relacionados à distribuição de água em todo o globo; fatos sobre pegadas hídricas em diversos países; fatos sobre poluição hídrica em todo o globo, com ênfase sobre contextos locais;

- Discutir e compreender o conceito de serviços ecossistêmicos (em geral e aplicado à água);

- Compreender os componentes sociais e ambientais, bem como suas relações, na constituição dos problemas socioambientais;

- Compreender e identificar os agentes da poluição ambiental e, especificamente, da poluição hídrica;

- Compreender como os resíduos sólidos podem ser reutilizados ou reciclados a fim de impedir ou reduzir a poluição ambiental;

- Compreender a importância da manutenção de parques e áreas verdes nas áreas urbanas;

- Compreender as relações entre meio ambiente e saúde;

- Compreender interações ecológicas (entre animais e plantas) e a relação entre fatores bióticos e abióticos no ecossistema;

- Compreender bases do ciclo da água e identificar seus aspectos interfronteiriços.

\section{Procedimentais}

- Analisar e construir argumentos acerca da poluição hídrica, das pegadas hídricas e de questões de valor, com ênfase sobre a dimensão ética, associadas ao uso da água;

- Identificar os possíveis responsáveis pela poluição em parques naturais;

- Relacionar a saúde do meio ambiente com o cuidado da nossa saúde; 
- Diferenciar as inúmeras atitudes humanas para com o meio ambiente;

- Esboçar mecanismos de como preservar o meio ambiente e os recursos naturais;

- Descrever, explicar e comparar fenômenos socioambientais relacionados ao uso da água e à poluição hídrica;

\section{Atitudinais}

- Discutir as ideias de valor instrumental e valor intrínseco das entidades e processos ecológicos (incluindo a água). Em particular, neste contexto, discutir e diferenciar valor econômico (monetário) e valor não econômico (respeito à vida, ao ambiente, à água, às identidades culturais locais) da natureza não-humana;

- Discutir a importância de se refletir sobre as razões para ações em que cabem juízo moral;

- Refletir criticamente de modo a diferenciar o que é considerado moralmente recomendável do que não é, na relação humana com o meio ambiente;

- Refletir criticamente sobre o consumo de bens materiais e os resíduos gerados, relacionando o tema com a poluição ambiental, sobretudo a poluição hídrica. Ainda, praticar hábitos relacionados a um consumo responsável;

- Compreender e praticar normas de boa convivência, de condutas adequadas em parques naturais etc. (por exemplo, não jogar lixo em ambientes naturais, mas sim, na lixeira; e, sempre que possível, separar lixo para reciclagem);

- Conhecer o sistema de gestão do parque, com base em leis ambientais;

- Compreender e respeitar o direito dos seres vivos à vida;

- Praticar o uso racional e adequado da água (em casa, na escola etc.);

- Praticar habilidades relacionadas ao trabalho coletivo (compreensão de diferentes pontos de vista, tolerância e trabalho colaborativo, solidariedade, respeito ao próximo etc.);

- Discutir com as comunidades sobre os problemas presentes em parques naturais, mobilizando-se para ações sociopolíticas;

- Promover a participação das decisões nos comitês de bacias hidrográficas da região, executando ações sociopolíticas.

\section{Meios para aplicação e discussão da QSC no ensino}

O caso proposto com base na QSC poderá ser aplicado como parte de uma sequência didática ou isoladamente. A contextualização do tema poluição hídrica deve ser realizada tomando como referência o local onde o estudante vive ou a localidade que melhor the sirva de referência. Isso deve ser considerado, uma vez que o problema socioambiental mais próximo pode lhes instigar mais o interesse e, assim, mais provavel- 
mente, isso pode ter papel positivo na tomada de decisão e no engajamento para ações com a comunidade do entorno.

O processo para tomada de decisão e ação responsável requer interesse e proximidade com o problema em questão. Santos e Mortimer (2001) propõem que a educação para a cidadania não seja aquela apresentada já com as soluções prontas para os estudantes; pois não se trata de fornecer a fórmula determinada da justiça, mas de apontar e refletir sobre os critérios para os juízos e suas dimensões éticas, permitindo ao indivíduo que determine, individual e coletivamente, os limites entre o aceitável e o inaceitável. Portanto, os professores não devem indicar precisamente quais as decisões certas ou adequadas, visto que o processo de tomada de decisão não implica apenas na capacidade de expressar ideias e argumentar, mas também na capacidade de avaliar as diferentes opiniões que surgem no debate e saber negociar uma solução de interesse comum. Dessa forma, os estudantes devem ser convidados a refletir sobre os problemas que lhes cercam, e buscar as soluções que são pertinentes.

Os valores discutidos e os conhecimentos (sobre o tema) devem subsidiar a melhor escolha das soluções apresentadas. A decisão escolhida deverá refletir a consciência e o compromisso com determinados valores explicitados e discutidos, além da capacidade de transformar atitudes, habilidades e valores em ações concretas (SANTOS; MORTIMER, 2001) para certos fins, que aqui defendemos. Para concretizar as ações sociopolíticas, por sua vez, sugerimos, por exemplo, o uso de ferramentas tecnológicas de mobilização sociopolítica, tais como: uso das redes sociais virtuais (no qual pode ser criado um grupo sobre o tema poluição hídrica ou pegada hídrica, em geral, ou sobre o problema específico relacionada à água no parque; a fim de informar e discutir o tema), produção de blogs, de vídeos, de entrevistas com moradores da comunidade local ou, por fim, a confecção de um jornal para divulgar dados e iniciativas junto à comunidade.

\section{Considerações finais}

A proposta de ensino baseada na QSC pode ser adotada como uma estratégia didática para possibilitar o diálogo e a ressignificação social da ciência, no ambiente escolar, ao possibilitar sua inserção no contexto das relações entre CTSA. Em particular, o caso proposto busca estabelecer uma relação de proximidade com a localidade onde o estudante vive, com os problemas ali enfrentados, com ênfase nos conteúdos atitudinais, fundamentados na ética ambiental.

Os conteúdos selecionados refletem os debates que ocorrem na ética ambiental e na sociedade, tais como: respeito à vida (perspectiva biocêntrica), conservação dos ecossistemas (perspectiva ecocêntrica), entendimento da posição dos seres humanos como parte do meio ambiente (perspectiva biocêntrica e ecocêntrica), atribuição de valor dado ao meio ambiente para análise dos serviços ecossistêmicos (perspectiva antropocêntrica), entre outros. 
Os conteúdos atitudinais debatidos podem indicar a importância de uma educação CTSA fundamentada em valores éticos para todos os cidadãos. Nesse sentido, é relevante adotar a educação CTSA logo no ensino fundamental, principalmente devido ao fato de ser uma fase de formação de caráter do indivíduo, que deve, portanto, ser rica em conteúdos atitudinais e que se estenda a outros níveis do ensino para a formação de cidadãos críticos, capazes de ações sociopolíticas que contribuam para maior justiça social e sustentabilidade ambiental.

\section{Referências}

AGÊNCIA NACIONAL DE ÁGUAS-ANA. Atlas Brasil: abastecimento urbano de água: resultados por estado. Brasília, DF, 2010.

ARANHA, M. L. de A. Filosofia da educação. 3. ed. São Paulo: Moderna, 2006.

BECKERT, C. Dilemas de ética ambiental: estudo de um caso. Lisboa: Apenas Livros, 2004.

BENCZE, L.; ALSOP, S. Ecojustice through responsibilist science education. In: ANNUAL CONFERENCE OF THE CANADIAN SOCIETY FOR THE STUDY OF EDUCATION, 2009. Ottawa. Proceeding... Otawa: Carleton University, 2009. p. 1-28.

BENCZE, J. L.; CARTER, L.; KRSTOVIC, M. Science \& technology education for personal, social \& environmental wellbeing: challenging capitalists' consumerist strategies. Revista Brasileira de Pesquisa em Educação em Ciências, Belo Horizonte, v. 14, n. 2, p. 39-56, 2014.

BERGANDI, D. Environnement, éthique et politique: les limites d'une démocratie inaboutie et leurs conséquences néfastes sur la protection de la nature. Éthique publique, Québec, v. 16, n. 1, 2014.

BERGANDI, D. The structural links between ecology, evolution and ethics: the virtuous epistemic circle. Dordrecht: Springer, 2013.

BERGANDI; D.; BLANDIN, P. From the protection of nature to sustainable development: the genesis of an ethical and political oxymoron. Revue D'histoire des Sciences, Evry, v. 65, n. 1, Jan./Jun., 2012.

BLANDIN, P. Towards EcoEvoEthics. In: BERGANDI, D. The structural links between ecology, evolution and ethics: the virtuous epistemic circle. Dordrecht: Springer, 2013. p. 83-100.

BRASIL. Manual de educação: consumo sustentável. Brasília, DF, 2005.

BRASIL. Ministério da Educação. Secretaria de Educação Fundamental. Parâmetros curriculares nacionais: terceiro e quarto ciclo, apresentação dos temas transversais. Brasília, 1998.

CAPONI, G. La ciencia de lo sustentable: razón de ser del discurso funcional en ecología. Principia, Florianópolis, v. 14, n. 3, p. 349-373, 2010. 
COLL, C. et al. Los contenidos en la reforma: enseñanza y aprendizaje de conceptos, procedimientos y actitudes. Madrid: Santillana, 1992.

CONRADO, D. M. et al. Evolução e ética na tomada de decisão em questões sociocientíficas. Revista Electrónica de Enseñanza de las Ciencias, Ourense, p. 803-807, 2013. Edição especial.

CONRADO, D. M.; EL-HANI, C. N.; NUNES-NETO, N. F. Sobre a ética ambiental na formação do biólogo. Revista Eletrônica do Mestrado em Educação Ambiental, Rio Grande, v. 30, n. 1, p. 120-139, jan./ jun. 2013.

CONRADO, D. M.; NUNES-NETO, N. F. Dimensões do conteúdo em questões sociocientíficas no ensino de ecologia. In: ENCONTRO NACIONAL DE EDUCAÇÃO EM CIÊNCIAS, 16., 2015, Lisboa. Anais... Lisboa: ENEC, 2015. p. 432-435.

COOPER, G. J.; EL-HANI, C. N.; NUNES-NETO, N. F. Three approaches to the teleological and normative aspects of ecological functions. In: ELDREDGE, N. et al. (Ed.). Evolutionary theory: a hierarchical perspective. Chicago: University of Chicago Press, 2016.

DE GROOT, R. S.; WILSON, M. A.; BOUMANS, R. M. J. A typology for the classification, description and valuation of ecosystem functions, goods and services. Ecological Economics, Amsterdam, v. 41, n. 2, p. 393-408, 2002.

DETONI, T. L.; DONDONI, P. C.; PADILHA, E. A. A escassez da água: um olhar global sobre a sustentabilidade e a consciência acadêmica. In: ENCONTRO NACIONAL DE ENGENHARIA DE PRODUÇÃO, 27., 2007, Iguaçu. Atas... Foz do Iguaçu: [S.n.], 2007.

FOUREZ, G. Educar: docentes, alunos, escolas, éticas, sociedades. Aparecida: Idéias e Letras, 2008.

GALLI, C. S.; ABE, D. S. Disponibilidade, poluição e eutrofização das águas. In: BICUDO, C. E. de M.; TUNDISI, J. G.; SCHEUENSTUHL, M. C. B. (Org.). Águas do Brasil: análises estratégicas. São Paulo: Instituto de Botânica, 2010. p. 165-174.

GIROUX, H. A.; GIROUX, S. S. Challenging neoliberalism's new world order: the promise of critical pedagogy. Cultural studies, critical methodologies, Thousand Oaks, v. 6, p. 21-32, 2006.

GÓMEZ-BAGGETHUN, E. et al. The history of ecosystem services in economic theory and practice: From early notions to markets and payment schemes. Ecological Economics, Amsterdam, v. 69, n. 1, p. 1209-1218, 2010.

GORCZEVSKI, C.; MARTIN, N. B. A necessária revisão do conceito de cidadania [recurso eletrônico]: movimentos sociais e novos protagonistas na esfera pública democrática. Santa Cruz do Sul: EDUNISC, 2011.

GRÜN, M. Ética e educação ambiental: a conexão necessária. 14. ed. Campinas: Papirus, 2012. 
HEMPEL, M. Ecoalfabetización: el conocimiento no es suficiente. In: GOBERNAR para la sostenibilidad: La situación del mundo 2014. Barcelona: Icaria editorial, 2014, p. 79-93.

HODSON, D. Going beyond STS: towards a curriculum for sociopolitical. Science Education Review, Queensland, v. 3, n. 1, p. 2-7, 2004.

HODSON, D. Looking to the future: building a curriculum for social activism.

Rotterdam: Sense Publishers, 2011.

HOEKSTRA, A.; MEKONNEN, M. M. The water footprint of humanity. Proceendings of the National Academy of Sciences of the Unites States of America, Washington, p. 32323237, v. 109, n. 9, 2012.

JAMIESON, D. Ética e meio ambiente: uma introdução. Tradução de André Luiz de Alvarenga. São Paulo: SENAC, 2010.

JAX, K. Ecosystem functioning. Cambridge: Cambridge University Press, 2010.

JAX, K. Function and "functioning" in ecology: what does it mean? Oikos, Oxford, v. 111, n. 3, p. 641-648, 2005.

JAX, K. et al. Ecosystem services and ethics. Ecological Economics, Amsterdam, v. 93, p. 260-268, 2013.

LARRERE C. Two philosophies of the environmental crises. In: BERGANDI, D. The structural links between ecology, evolution and ethics: the virtuous epistemic circle. Dordrecht: Springer, 2013. p. 141-149.

LIGHT, A.; ROLSTON III, H. Environmental ethics: an anthology. Oxford: WileyBlackwell, 2003.

MCCAULEY, D. J. Selling out on nature, Nature, London, v. 443, n. 7, p. 27-28, Sept. 2006.

MEKONNEN, M. M.; HOEKSTRA, A. Y. National water footprint accounts: the green, blue and grey water footprint of production and consumption. Delft: UNESCO, 2011. (Value of Water Research Report Series, n. 50).

MILLENNIUM ECOSYSTEM ASSESSMENT. Ecosystems and human well-being: desertification synthesis. Washington: World Resources Institute, 2005.

NORTON, B. Environmental ethics and weak anthropocentrism. Environmental Ethics, Denton, v. 6, n. 2, p. 131-148, 1984.

NORTON, B. Searching for sustainability: interdisciplinary essays in the philosophy of conservation biology. Cambridge: Cambridge University Press, 2003.

NORTON, B. Facts, values, and analogies: a Darwinian approach to environmental choice. In: BERGANDI, D. The structural links between ecology evolution and ethics: the virtuous epistemic circle. Dordrecht: Springer, 2013. p. 63-82. 
NUNES-NETO, N. F. The environmental crisis as a good case for an intellectual and practical integration between philosophy and science. Science \& Education, Dordrecht, p. 1285-1299, 2015.

NUNES-NETO, N. F. O discurso funcional na ecologia contemporânea. 2013. 95 f. Tese (Doutorado em Ecologia e Biomonitoramento) - Universidade Federal da Bahia, Salvador, 2013.

NUNES-NETO, N. F.; CARMO, R. S.; EL-HANI, C. N. O conceito de função na ecologia contemporânea. Revista de Filosofia Aurora, Curitiba, v. 25, n. 36, p. 43-73, 2013.

NUNES-NETO, N.; MORENO, A; EL-HANI, C. Function in ecology: an organizational approach. Biology and Philosophy, Dordrecht, v. 29, n. 1, p. 123-141, 2014.

NUNES-NETO, N.; CARMO, R.; EL-HANI, C. Biodiversity and ecosystem functioning: an analysis of the functional discourse in contemporary ecology. Filosofia e História da Biologia, São Paulo, v. 11, n. 2, p. 289-321, 2016.

PEDRETTI, E.; NAZIR, J. Currents in STSE Education: Mapping a Complex Field, 40 Years On, Science Education, Salem, v. 95, n. 4, p. 601-626, 2011.

REGAN, T. Empty cages: Facing the challenge of animal rights. Oxford: Rowman \& Littlefield Publishers. 2003.

REGAN, T. Animal Rights and Environmental Ethics. In: BERGANDI, D. (Ed.). The structural links between ecology, evolution and ethics: the virtuous epistemic circle. Dordrecht: Springer, 2013. p. 117-126.

SANTOS, J.; CONRADO, D. M.; NUNES-NETO, N. F. Ética ambiental a partir de questões sociocientíficas no ensino fundamental. In: ENCONTRO REGIONAL DE ENSINO DE BIOLOGIA DO NORDESTE, 6., 2015. Vitória da Conquista. Anais... Vitória da Conquista: Universidade Estadual do Sudoeste da Bahia. 2015. p. 1-10.

SANTOS, J.; CONRADO, D. M.; NUNES-NETO, N. F. Questões sociocientíficas no ensino fundamental de ciências: uma experiência com poluição de águas. Indagatio Didactica, Aveiro, v. 8, n. 1, p. 1051-1067, 2016.

SANTOS, W. L. P. dos; MORTIMER, E. F. Tomada de decisão para ação social responsável no ensino de ciências. Ciência e Educação, Bauru, v. 7, n. 1, p. 95-111, 2001. SILVA, J. M. da. Ética prática: contributos para as políticas da água. Lisboa: Sociedade de Ética Ambiental: Apenas Livros, 2009.

SINGER, P. Ética prática. 3. ed. São Paulo: Martin Fontes, 2002.

SINGER, P. Libertação Animal. Porto Alegre: Lugano, 2010.

TAYLOR, P. Respect for nature. Environmental Ethics, Denton, v. 3, n. 3, p. 197-218, 1981. 
TEIXEIRA, P. M. M. Educação científica e movimento C.T.S. no quadro das tendências pedagógicas no Brasil. Revista Brasileira de Pesquisa em Educação em Ciências, Porto Alegre, v. 3, n. 1, p. 88-102, 2003.

TELES, M. O valor moral da natureza: reflexões a partir da teoria axiológica de Tom Regan. Lisboa: Sociedade de Ética Ambiental: Apenas Livros, 2007. (Breviário de Ética Ambiental, n. 5).

VAZ, S. G.; DELFINO, A. Manual de ética ambiental. Lisboa: Universidade Aberta, 2010.

VICTORINO, C. J. A. Planeta água morrendo de sede: uma visão analítica na metodologia do uso e abuso dos recursos hídricos. Porto Alegre: EDIPUCRS, 2007.

WORLD WIDE FOUND FOR NATURE - WWF. Living Planet Report 2014: Summary. Gland, 2014.

ZABALA, A. A prática educativa: como ensinar. Porto Alegre: Artes Médicas Sul, 1998.

ZABALA, A.; ARNAU, L. Como aprender e ensinar competências. Porto Alegre: Artmed, 2010.

ZEIDLER, D. L. et al. Beyond STS: a research-based framework for socioscientific issues education. Science Education, Salem, v. 89, n. 3, p. 357-377, 2005. 